\title{
Multipass Turning Operation Process Optimization Using Hybrid Genetic Simulated Annealing Algorithm
}

\author{
Abdelouahhab Jabri, Abdellah El Barkany, and Ahmed El Khalfi \\ Laboratory of Mechanical Engineering, Faculty of Sciences and Techniques, University of Sidi Mohamed Ben Abdellah, Fes, Morocco \\ Correspondence should be addressed to Abdelouahhab Jabri; abdelouahhab.jabri@gmail.com
}

Received 4 March 2017; Accepted 8 May 2017; Published 21 June 2017

Academic Editor: Enmin Feng

Copyright ( 2017 Abdelouahhab Jabri et al. This is an open access article distributed under the Creative Commons Attribution License, which permits unrestricted use, distribution, and reproduction in any medium, provided the original work is properly cited.

\begin{abstract}
For years, there has been increasing attention placed on the metal removal processes such as turning and milling operations; researchers from different areas focused on cutting conditions optimization. Cutting conditions optimization is a crucial step in Computer Aided Process Planning (CAPP); it aims to select optimal cutting parameters (such as cutting speed, feed rate, depth of cut, and number of passes) since these parameters affect production cost as well as production deadline. This paper deals with multipass turning operation optimization using a proposed Hybrid Genetic Simulated Annealing Algorithm (HSAGA). The SAbased local search is properly embedded into a GA search mechanism in order to move the GA away from being closed within local optima. The unit production cost is considered in this work as objective function to minimize under different practical and operational constraints. Taguchi method is then used to calibrate the parameters of proposed optimization approach. Finally, different results obtained by various optimization algorithms are compared to the obtained solution and the proposed hybrid evolutionary technique optimization has proved its effectiveness over other algorithms.
\end{abstract}

\section{Introduction}

Metal removal processes such as turning operations involve different variables ranging from input variables (cutting speed, feed rate, depth of cut, and number of passes) to output variables (production cost, production time, tool life, dimensional accuracy, surface roughness, cutting forces, cutting temperature, and power consumption, etc.). Selecting appropriate cutting conditions has a significant impact on machining cost, product quality, and manufacturing cycle-time. These parameters are feed rate (f), speed of cut (V), depth of cut (d), and number of passes (n). Turning operation can be illustrated in Figure 1.

The first paper related to parameter selection problem of multipass turning presented by Shin and Joo [1] initiated a series of studies. Authors from different backgrounds attempted optimization of the same problem using various optimization approaches $[2,3]$.

Chen and Tsai [4] proposed a hybrid technique based on Simulated Annealing Algorithm and the Hooke-Jeeves pattern search (SA-PS) to minimize the unit production cost;
Onwubolu and Kumalo [5] presented an optimization based on Genetic Algorithm approach and have shown that GA optimization technique gives better results than [4]. However, M.-C. Chen and K.-Y. Chen [6] demonstrated that the result obtained by [5] was invalid, due to incorrect handling of the equality constraint of cutting depth. Vijayakumar et al. [7] have attempted the same problem using the Ant Colony Optimization (ACO) Algorithm. Subsequently, Wang [8] proved that the optimal solution, as found by [7], was also not valid. Srinivas et al. [9] used Particle Swarm Optimization (PSO) to minimize the unit production cost similarly to Chen and Tsai [4].

In the last decade, hybrid optimization techniques continue to attract more researchers by their ability to solve complex combinatorial optimization problems and various combinations approaches have been proposed by several authors. Costa et al. [10] proposed a Hybrid Particle Swarm Optimization (HPSO) technique for solving multipass turning optimization problem as presented by [4]. Lee and Ponnambalam [11] used a hybrid algorithm by combining the GA and the Artificial Immune Algorithm and attempted the same 


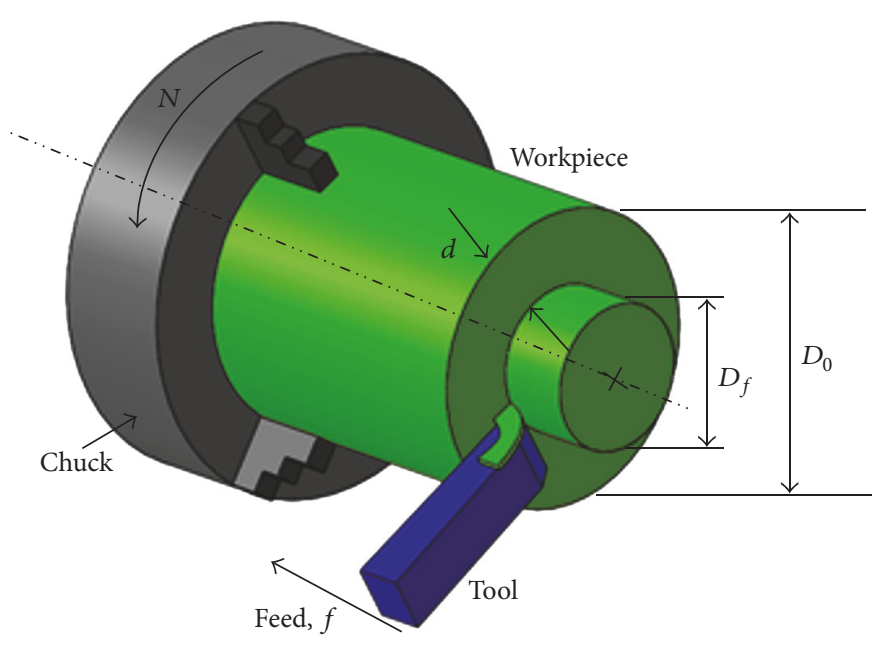

FIgURE 1: Example of turning operation.

model as [7]. Xie and Guo [12] combined Ant Colony Optimizations (ACO) with a Pass Enumerating method to minimize unit production cost as well as [4].

Yildiz implemented several optimization techniques for solving the multipass turning operations problem, such as hybrid approach based on the Differential Evolution algorithm [13], Hybrid Robust Differential Evolution (HRDE) algorithm [14], Hybrid Artificial Bee Colony algorithm [15], and Hybrid Robust Teaching-Learning-Based Optimization (HRTLBO) algorithm [16] and hybrid PSO combined with Receptor Editing property of immune system [17]. However, any information about the optimal values of the machining parameters was provided.

Aryanfar and Solimanpur [18] presented an optimization of multipass turning operation based on GA technique which aims to minimize the unit production cost. Jabri et al. [19] proposed GA approach to solve a multiobjective problem where machining cost and tool life cost are simultaneously optimized. Rao and Kalyankar [20] used the TeachingLearning-Based Optimization algorithm to solve the same problem (multipass turning operation). They concluded that the TLBO can converge to the optimal solution within a lower number of iterations. Belloufi et al. [21] proposed a Firefly Algorithm (FA), but constraint limitation such as cutting force was incorrectly handled.

Mellal and Williams [22] utilized Cuckoo optimization algorithm seeking to minimize production cost and comparing the obtained results with previously published results. In this study, the algorithm obtained the known optimal parameters in one case but failed in another. Chauhan et al. [23] proposed a Totally Disturbed Particle Swarm Optimization (TDSPO) for this problem where the phenomenon of chaos is embedded at PSO in order to disturb the particles at later iterations to prevent stagnation. Compared with the basic PSO the proposed method has given best results. Gayatri and Baskar [24] developed a sequential hybrid approach which is a fusion of GA, SA, and PSO optimization techniques to solve the multipass turning problem. In their work, three different selection methods of GA are studied which are linear ranking, tournament selection, and roulette wheel selection; the former method is the best selection method of GA technique and the hybrid approach has proven effectiveness when compared to each one. Another work related to the multipass turning problem is recently published [25]; it is based on a novel optimization technique called Flower Pollination Algorithm (FPA). The global and local search operators made of this optimization technique a powerful approach and it has given satisfactory results.

As presented in the above literature review, turning process is a complex problem to solve since it involves numerous elements. In fact, various optimization approaches are proposed by authors from different areas hoping to improve quality results in terms of precision and computational time. Unfortunately, it appears that more efforts are needed to be made to assist the process planner with reliable tool while selecting best machining parameters. In this work, a Hybrid Genetic Simulated Annealing Algorithm is developed to minimize the unit production cost of multipass turning process; the performance of the proposed optimization approach is highlighted by comparing the obtained results with different optimal costs presented by various optimization techniques.

The rest of the paper is organized as follows. In the next section, we present the problem concerned which is an objective function to minimize subject to various operational and practical constraints. In Section 3 the proposed hybrid algorithm optimization for multipass turning operation is presented. Parameters calibration of the proposed algorithm is then studied and obtained results are presented and compared to previously published works in Section 4. Finally, concluding remarks and some possible future works are given.

\section{Multipass Turning Mathematical Model}

The mathematical model of multipass turning operation proposed by [1] has remained a topic of interest for researchers; it is adopted in the present paper and the unit production cost subject to constraints will be minimized. Constraints 
including parameter bounds and cutting condition restraints on the tool and the workpiece are taken into account in this study. A detailed presentation of the objective and the constraints is given below.

2.1. Objective Function. The unit production cost, UC, for multipass turning operations can be divided into four basic cost elements.

(i) Cutting cost by actual time:

$$
C_{M}=k_{0} \times\left[\frac{\pi D L}{1000 V_{r} f_{r}}\left(\frac{d_{t}-d_{s}}{d_{r}}\right)+\frac{\pi D L}{1000 V_{s} f_{s}}\right] .
$$

(ii) Machine idle cost due to loading and unloading operations and idling tool motion:

$$
C_{l}=k_{0} \times\left[t_{c}+\left(h_{1} L+h_{2}\right)\left(\frac{d_{t}-d_{s}}{d_{r}}+1\right)\right] .
$$

(iii) Tool replacement cost:

$$
C_{R}=k_{0} \times \frac{t_{e}}{T_{p}}\left[\frac{\pi D L}{1000 V_{r} F_{r}}\left(\frac{d_{t}-d_{s}}{d_{r}}\right)+\frac{\pi D L}{1000 V_{s} f_{s}}\right] .
$$

(iv) Tool cost:

$$
C_{T}=\frac{k_{t}}{T_{p}}\left[\frac{\pi D L}{1000 V_{r} f_{r}}\left(\frac{d_{t}-d_{s}}{d_{r}}\right)+\frac{\pi D L}{1000 V_{s} f_{s}}\right],
$$

where

$$
T_{p}=\theta T_{r}+(1-\theta) T_{s} \quad T_{r}=\frac{C_{0}}{V_{r}^{p} f_{r}^{q} d_{r}^{r}} T_{s}=\frac{C_{0}}{V_{s}^{p} f_{s}^{q} d_{s}^{r}} .
$$

Finally, objective function which is the sum of these costs can be expressed as follows:

$$
\min (\mathrm{UC})=\min [g(x)]=\min \left(C_{M}+C_{l}+C_{R}+C_{T}\right)
$$

2.2. Constraints. Constraints are technical and operational limitations that should be taken into consideration during the roughing and finishing operations. These constraints involve parameter bounds, operating constraints, and cutting condition relations.

\section{(i) Parameter Bounds}

$$
\begin{aligned}
& V_{L} \leq V_{r} \leq V_{U}, \\
& f_{L} \leq f_{r} \leq f_{U} \\
& d_{L} \leq d_{r} \leq d_{U} \\
& V_{L} \leq V_{s} \leq V_{U}, \\
& f_{L} \leq f_{s} \leq f_{U}, \\
& d_{L} \leq d_{s} \leq d_{U} .
\end{aligned}
$$

(ii) Operating Constraints. The cutting force and the power constraints for both roughing and finishing operations are expressed as follows:

$$
\begin{aligned}
& F_{r}=108 \times f_{r}^{\mu} d_{r}^{v} \leq F_{U}, \\
& F_{s}=108 \times f_{s}^{\mu} d_{s}^{v} \leq F_{U}, \\
& P_{r}=\frac{f_{r} V_{r}}{6120 \times \eta} \leq P_{U}, \\
& P_{s}=\frac{f_{s} V_{s}}{6120 \times \eta} \leq P_{U} .
\end{aligned}
$$

The chip-tool interface constraint of (10) follows the formulation of Hati and Rao (1976) [26]:

$$
\begin{aligned}
& Q_{r}=k_{2} V_{r}^{\tau} f_{r}^{\varphi} d_{r}^{\delta} \leq Q_{U}, \\
& Q_{s}=k_{2} V_{s}^{\tau} f_{s}^{\varphi} d_{s}^{\delta} \leq Q_{U} .
\end{aligned}
$$

The stable cutting region constraint of (11) and the surface finish constraint of (17) follow the formulation of Narang and Fischer (1993) [27]:

$$
\begin{aligned}
V_{r}^{\lambda} f_{r} d_{r}^{v} & \geq \mathrm{SC}_{U}, \\
V_{s}^{\lambda} f_{s} d_{s}^{v} & \geq \mathrm{SC}_{U}, \\
\frac{f_{s}^{2}}{8 \times R} & \leq \mathrm{SR}_{U} .
\end{aligned}
$$

(iii) Cutting Parameter Relations

$$
\begin{aligned}
& V_{s} \geq k_{3} V_{r}, \\
& f_{r} \geq k_{4} f_{s}, \\
& d_{r} \geq k_{5} d_{s}, \\
& d_{r}=\frac{d_{t}-d_{s}}{n} .
\end{aligned}
$$

\section{Proposed Solution Algorithm}

The proposed HSAGA is based on the combination between the GA algorithm and SA-based local search. In this section we present a brief overview on SA and GA techniques. GA is a randomized global search technique that solves problems by imitating processes observed from natural evolution; it has been introduced by Holland in 1960s and further described by Goldberg [28]. So far, GA has been successfully adopted in many complex optimization problems and shows its merits over traditional optimization methods. GA starts with a population of candidate solutions that evolves to reach near optimal solution. Each candidate is usually coded as a binary string "chromosome" in order to undergo reproduction; the fitness of each individual is then evaluated after the operation of decoding chromosome. 
On the other hand, The SA algorithm mimics the behaviour of a physical system that is heated and then cooled slowly, such as growing crystals or annealing metals. Presented for the first time by Kirkpatrick et al. [29], it can be used to solve many combinatorial process optimization problems. This technique starts with selection of an initial random process decision vector and moves to new neighbourhood decision vector that improves objective function value. SA technique may accept inferior decision vector based on certain probabilistic measure " $\overline{\bar{p}}$ " called the Boltzmann statistics (see (18)), which helps the algorithm to escape entrapment in local optima and eventually reach the global optima:

$$
\overline{\bar{p}}=\exp ^{(-\Delta E / T)},
$$

where $\Delta E$ represents the difference in the objective value between the generated solution $x^{\prime}$ and the current solution $x$ (see (19)). " $T$ " is the annealing initial temperature

$$
\Delta E=g\left(x^{\prime}\right)-g(x) .
$$

GA optimization technique has strong global search ability, but it also has limitations such as a premature and slow convergence rate, as well as weak local search ability. On the other hand, SA algorithm has strong local search ability and no premature problems. In this paper, a Hybrid Simulated Annealing Genetic Algorithm (HSAGA) is proposed to overcome the limits of each of the two techniques, bringing into play their respective advantages, and improve the solving efficiency.

3.1. Initialization. In this step of Genetic Algorithm a population of individuals (for each variable) is generated using the random uniform distribution in the defined interval, for both roughing and finishing operations. Feed rate $(\mathbf{f})$ is a real number generated between $\left[f_{L}, f_{U}\right]$; cutting speed $(\mathbf{V})$ and depth of cut $(\mathbf{d})$ are integer numbers generated in the ranges $\left[V_{L}, V_{U}\right],\left[d_{L}, d_{U}\right]$, respectively. In order to take into account the relation between $d_{r}$ and $d_{s}$, the depth of cut of roughing is derived, subject to the fact that they lie between the accepted limits of $\left[d_{L}, d_{U}\right]$. It should be noted that the population size "Popsize" has a considerable impact on quality solution and computational duration; thus it needs to be fixed at the appropriate value. Each element of the solution space " $x$ " has a cost value obtained using the objective function: $g(x)$.

3.2. Evaluation and Constraints Handling. The purpose of this optimization is to compute the minimal cost of a turning operation. A score function value is associated with each element of solution space (competitiveness). The penalty function is used to penalize the individuals who violate the constraints. The more the constraints are violated, the heavier the penalty will be done. As a result, the fitness of them will be small. In this way, unfeasible solutions have more chance to be eliminated from the solution space. Using the objective function the probability of selection is calculated as follows:

$$
e^{i}=\frac{\Delta \tilde{g}}{\sum_{i=1}^{\text {pop_size }} \Delta \tilde{g} / \text { pop_size }},
$$

where

$$
\Delta \tilde{g}=g_{\text {worst }}-g^{i}
$$

$g^{i}$ is the value of objective function of the current element " $i$ ". $g_{\text {worst }}$ is the worst value of the current solution space (the maximum value of objective function).

The probability $e^{i}$ gives to the element the chance to be reproduced based on its competitiveness.

3.3. Solution Encoding. Individuals which represent machining parameters have to undergo some genetic operations such as crossover and mutation. To do so, they should be encoded appropriately. A proper encoding scheme, which is indicative of the characteristics of a solution, has considerable influence on the performance of quality solution. In this step we adopt the same encoding scheme of [4] where individuals represented as string-bit block called (chromosomes) are converted to a binary string and allocated to a 22-bit block.

The operation of converting each individual to a binary string from a real number " $a$ " to a binary string $\left\{b_{21}, b_{20}, \ldots, b_{0}\right\}$ is calculated by using the following equation:

$$
a^{\prime}=\frac{a+2.0}{4 /\left(2^{22}-1\right)} \text {. }
$$

$a^{\prime}$ is then transformed to a binary string. For example, a feed rate value of " 0.729 " has a string bock as follows:

$$
(1010111010100111111001)_{2} \text {. }
$$

With this representation genetic operators can be applied to individuals and they can be reconverted into integer or real number again, using the binary mapping technique.

\subsection{Genetic Simulated Annealing Operators Perturbation}

3.4.1. Two Cut-Points Crossover. Crossover is a mechanism for diversification that encourages GA to examine unvisited regions. Two-point crossover calls for two randomly generated points to be selected on the parent strings and all bits between the two points are swapped between the parent strings, rendering two child strings. For example, two strings of the first block, having cutting speed values of 78 and $108 \mathrm{~m} / \mathrm{min}$, respectively, after crossover operation, become 110 and $76 \mathrm{~m} / \mathrm{min}$, respectively:

\section{String 1: 0000000000000001'001'110}

$$
\text { String 2: 0000000000000001'101'100 }
$$

New String 1: 0000000000000001 '101'110

$$
\text { New String 2: } 0000000000000001 \text { '001'100 }
$$

3.4.2. Mutation and Neighbourhood Principle. Mutation is a random modification of randomly selected bits. This operator performs modification into chromosomes with certain probability " $P_{m}$ " and is considered as a perturbation mechanism to explore neighbours of possible solutions. For example, the 
previous new strings 1 (mutated positions are underlined) become

New String 1: $0000000000000001 \underline{001110 .}$

Applying the crossover and mutation operations, new different individuals from parent strings are generated. The metropolis acceptance criterion expressed by (19) is then applied to select which of individuals go into the next generation. In fact, the Old_pop and New_pop go to the next generation through competition; throughout this competition, two elements are extracted from the new solution: $f \_$newbest and $f \_$worst (the minimum and the maximum solutions of the offspring individuals, resp.). The algorithm accepts replacing the old solution in two cases:

(i) 1st case: if $f \_n e w b e s t$ is inferior to $f \_b e s t$ (the best solution of the parents population)

(ii) 2nd case: when $f \_n e w b e s t$ is superior to $f \_b e s t$ and the probability $p$ expressed by (19) is superior to random value generated between $[0,1]$

3.5. Cooling Schedule and Termination Condition. In this paper, the linear pattern of temperature reduction has been used, where the temperature is obtained from the following equation:

$$
T_{t+1}=\alpha \times T_{t}
$$

The termination condition is when the program makes $k$ iterations without improvement of the best solution. The HSAGA algorithm is shown in Algorithm 1.

\section{Results and Discussion}

In this section, minimization of unit production cost as reported in the literature is considered. The hybrid SAGA optimization technique is conducted in order to compute the optimal machining parameters of the metal cutting problem. The example considered is a cylindrical workpiece with $500 \mathrm{~mm}$ length and $50 \mathrm{~mm}$ diameter and the desired depth to cut is $6 \mathrm{~mm}$. Machining data is given in Table 1 .

The hybrid SAGA is written in python 3.5 and runs on Intel(R) Core(TM) i5-2430M CPU @2.4 GHz, with 4 GB of RAM. A set of parameters are involved in the proposed algorithm; Table 2 shows this optimization algorithm parameters. As shown in the second column, a range is given for each parameter. Thus, a tuning parameter is needed to select the best values that ensure the program convergence and stability.

4.1. Parameters Tuning. In this stage, Taguchi method is used to select suitable combination of the above-mentioned factors levels. Widely used in robust design, Taguchi technique is a universal approach [30]. The robust parameter design is based on the minimization of the sensitivity of noise by determination of factors levels. In such optimization, the response at each setting of parameters is treated as a measure to indicate the mean and the variance of some quality characteristics. These two indicators are combined into a

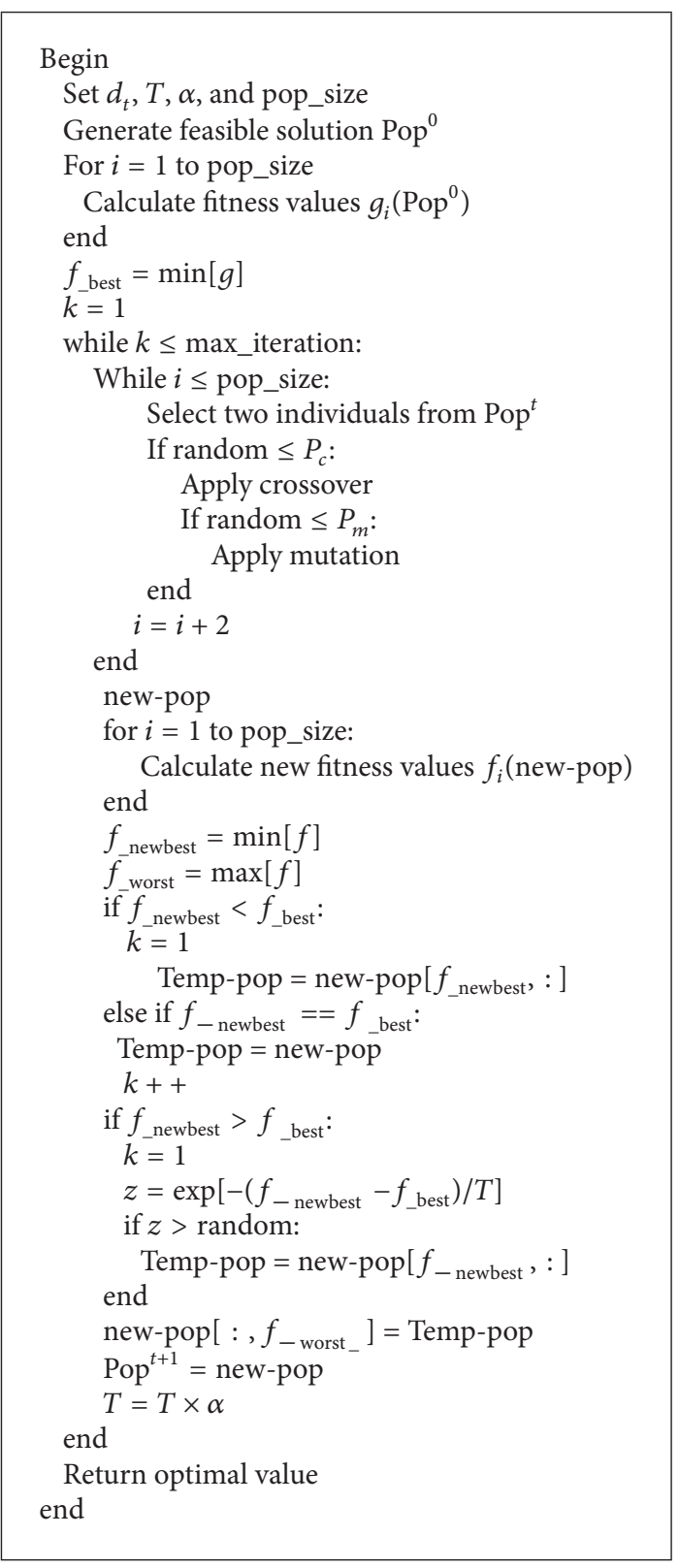

Algorithm 1: HSAGA proposed algorithm.

single performance measure so called the signal-to-noise $(S / N)$ ration. Taguchi proposed different categories of robust parameter design, smaller better, larger better, and so on [31]. The category smaller better is the suitable function for our problem, and it is expressed by

$$
\frac{S}{N}=-10 \log _{10}\left(\frac{1}{n} \sum_{i=1}^{n} \frac{1}{y_{i}^{2}}\right),
$$

where $j, y_{i}$, and $n$ denote the trial number, response variable, and the number of replications, respectively. In the proposed algorithm, seven factors should be calibrated, each with three levels. 
TABLE 1: Machining data.

\begin{tabular}{|c|c|}
\hline Parameter & Value \\
\hline$D$ & $50 \mathrm{~mm}$ \\
\hline$C_{0}$ & $6 \cdot 10^{11}$ \\
\hline$V_{s U}$ & $500 \mathrm{~m} / \mathrm{min}$ \\
\hline$f_{r U}$ & $0.9 \mathrm{~mm} / \mathrm{rev}$ \\
\hline$d_{r L}$ & $1 \mathrm{~mm}$ \\
\hline$d_{s U}$ & $3 \mathrm{~mm}$ \\
\hline$F_{U}$ & $200 \mathrm{Kgf}$ \\
\hline$Q_{U}$ & $1000^{\circ} \mathrm{C}$ \\
\hline$k_{1}$ & 108 \\
\hline$k_{4}$ & 2.5 \\
\hline$Q$ & 1.75 \\
\hline$v$ & 0.95 \\
\hline$v$ & -1 \\
\hline$R$ & $1.2 \mathrm{~mm}$ \\
\hline$k_{t}$ & $2.5 \$ / \mathrm{min}$ \\
\hline$t_{c}$ & $0.75 \mathrm{~min} /$ piece \\
\hline$L$ & $300 \mathrm{~mm}$ \\
\hline$V_{r U}$ & $500 \mathrm{~m} / \mathrm{min}$ \\
\hline$V_{s L}$ & $50 \mathrm{~m} / \mathrm{min}$ \\
\hline$f_{s L}$ & $0.1 \mathrm{~mm} / \mathrm{rev}$ \\
\hline$d_{r U}$ & $3 \mathrm{~mm}$ \\
\hline$T_{L}$ & $25 \mathrm{~min}$ \\
\hline$P_{U}$ & $5 \mathrm{KW}$ \\
\hline$\theta$ & 0.5 \\
\hline$k_{2}$ & 132 \\
\hline$k_{5}$ & 1.0 \\
\hline$R$ & 0.75 \\
\hline$\eta$ & 0.85 \\
\hline$\tau$ & 0.4 \\
\hline$\delta$ & 0.105 \\
\hline$h_{1}$ & $7 \cdot 10^{-4}$ \\
\hline$d_{t}$ & $6 \mathrm{~mm}$ \\
\hline$V_{r L}$ & $50 \mathrm{~m} / \mathrm{min}$ \\
\hline$f_{r L}$ & $0.1 \mathrm{~mm} / \mathrm{rev}$ \\
\hline$f_{s U}$ & $0.9 \mathrm{~mm} / \mathrm{rev}$ \\
\hline$d_{s L}$ & $1 \mathrm{~mm}$ \\
\hline$T_{U}$ & $45 \mathrm{~min}$ \\
\hline SC & 140 \\
\hline $\mathrm{SR}_{U}$ & $10 \mu \mathrm{m}$ \\
\hline$k_{3}$ & 1.0 \\
\hline$P$ & 5 \\
\hline$\mu$ & 0.75 \\
\hline$\lambda$ & 2 \\
\hline$\varphi$ & 0.2 \\
\hline$k_{0}$ & $0.5 \$ / \mathrm{min}$ \\
\hline$h_{2}$ & 0.3 \\
\hline$t_{e}$ & $1.5 \mathrm{~min} / \mathrm{edge}$ \\
\hline
\end{tabular}

TABLE 2: HSAGA parameters.

\begin{tabular}{lc}
\hline Parameters & Range/values \\
\hline Population size (Popsize) & $20-100$ \\
Maximum iteration number & $50-200$ \\
Crossover probability $(P c)$ & $70 \%-80 \%$ \\
Mutation probability $(P m)$ & $10 \%-30 \%$ \\
Initial temperature & $500-900$ \\
Cooling rate $(\alpha)$ & $0.70-0.90$ \\
Penalty $(\$)$ & $1-10$ \\
\hline
\end{tabular}

The selected L27 orthogonal array has 27 different combinations of parameter levels, which means that a total of 27 tests are conducted, and each test is replicated five times in order to obtain more reliable results. Table 3 shows the obtained results of each combination of factors proposed by Taguchi method.

To illustrate the performance of Taguchi method, Figure 2 presents evolution of mean $\mathrm{S} / \mathrm{N}$ ratios of each factor. The levels with the highest values of $\mathrm{S} / \mathrm{N}$ ratio are selected as the optimal value for each of them; these parameters values are gathered in Table 4.

4.2. Comparisons with Other Results. Using the abovementioned algorithm factors, optimal cutting parameters are obtained and related minimal cost is $2.06 \$$. Table 5 summarizes the optimal machining parameters, constraints values, and limitation; meanwhile it can be seen clearly that all constraints are respected. Moreover, convergence curves of the unit cost using HSAGA are given in Figure 3. It can be observed from this figure that obtained costs solutions are the same for each test, which indicates that the proposed algorithm with selected parameter values based on Taguchi method has good stability.

As presented in the Introduction, there are abundant results in the literature which make it important to compare our results with the others. The hybrid approach, used for the work reported here, is compared with obtained results of some research papers cited previously in the literature. Table 6 shows that our optimization technique gives better solution compared to other optimization approaches.

\section{Conclusion}

This work deals with metal removal process and particularly multipass turning operation. A new proposed optimization approach is applied to find minimum unit production cost of this turning operation. This approach is based on combination of SA local search technique with GA global optimization providing a strong possibility to GA of avoiding local minima and having a marked improvement of its performance. Compared to various optimization techniques, obtained results show that HSAGA is an efficient optimization technique and it can be interesting to be implemented in CAPP. 
TABLE 3: L27 orthogonal array.

\begin{tabular}{|c|c|c|c|c|c|c|c|c|c|c|c|}
\hline Popsize & Temp & $P c$ & Cool-Rate & $P m$ & Max-It & Pen. & $y_{1}$ & $y_{2}$ & $y_{3}$ & $y_{4}$ & $y_{5}$ \\
\hline 20 & 500 & 0,70 & 0,7 & 0,10 & 50 & 1 & 2,34 & 2,39 & 2,79 & 3,06 & 3,05 \\
\hline 20 & 500 & 0,70 & 0,7 & 0,15 & 100 & 5 & 3,15 & 2,39 & 2,50 & 2,15 & 2,70 \\
\hline 20 & 500 & 0,70 & 0,7 & 0,20 & 200 & 10 & 2,61 & 2,41 & 2,63 & 2,70 & 2,16 \\
\hline 20 & 750 & 0,75 & 0,8 & 0,10 & 50 & 1 & 2,46 & 2,76 & 2,26 & 2,51 & 2,45 \\
\hline 20 & 750 & 0,75 & 0,8 & 0,15 & 100 & 5 & 4,74 & 2,34 & 3,16 & 2,87 & 2,08 \\
\hline 20 & 750 & 0,75 & 0,8 & 0,20 & 200 & 10 & 3,11 & 2,21 & 2,18 & 2,50 & 2,48 \\
\hline 20 & 900 & 0,80 & 0,9 & 0,10 & 50 & 1 & 2,68 & 2,55 & 3,11 & 2,08 & 2,40 \\
\hline 20 & 900 & 0,80 & 0,9 & 0,15 & 100 & 5 & 3,59 & 2,07 & 2,37 & 2,56 & 2,49 \\
\hline 20 & 900 & 0,80 & 0,9 & 0,20 & 200 & 10 & 3,14 & 3,11 & 2,55 & 2,87 & 2,32 \\
\hline 50 & 500 & 0,75 & 0,9 & 0,10 & 100 & 10 & 2,18 & 2,21 & 2,07 & 2,07 & 2,44 \\
\hline 50 & 500 & 0,75 & 0,9 & 0,15 & 200 & 1 & 2,07 & 2,08 & 2,07 & 2,08 & 2,08 \\
\hline 50 & 500 & 0,75 & 0,9 & 0,20 & 50 & 5 & 2,44 & 2,21 & 2,07 & 2,48 & 2,09 \\
\hline 50 & 750 & 0,80 & 0,7 & 0,10 & 100 & 10 & 2,18 & 2,08 & 2,21 & 2,07 & 2,19 \\
\hline 50 & 750 & 0,80 & 0,7 & 0,15 & 200 & 1 & 2,18 & 2,08 & 2,08 & 2,18 & 2,07 \\
\hline 50 & 750 & 0,80 & 0,7 & 0,20 & 50 & 5 & 2,21 & 2,08 & 2,39 & 2,08 & 2,07 \\
\hline 50 & 900 & 0,70 & 0,8 & 0,10 & 100 & 10 & 2,07 & 2,07 & 2,07 & 2,19 & 2,08 \\
\hline 50 & 900 & 0,70 & 0,8 & 0,15 & 200 & 1 & 2,21 & 2,07 & 2,07 & 2,19 & 2,07 \\
\hline 50 & 900 & 0,70 & 0,8 & 0,20 & 50 & 5 & 2,19 & 2,07 & 2,17 & 2,08 & 2,07 \\
\hline 100 & 500 & 0,80 & 0,8 & 0,10 & 200 & 5 & 2,20 & 2,08 & 2,07 & 2,07 & 2,21 \\
\hline 100 & 500 & 0,80 & 0,8 & 0,15 & 50 & 10 & 2,07 & 2,08 & 2,07 & 2,07 & 2,12 \\
\hline 100 & 500 & 0,80 & 0,8 & 0,20 & 100 & 1 & 2,07 & 2,07 & 2,07 & 2,07 & 2,12 \\
\hline 100 & 750 & 0,70 & 0,9 & 0,10 & 200 & 5 & 2,08 & 2,07 & 2,07 & 2,08 & 2,08 \\
\hline 100 & 750 & 0,70 & 0,9 & 0,15 & 50 & 10 & 2,08 & 2,12 & 2,10 & 2,07 & 2,08 \\
\hline 100 & 750 & 0,70 & 0,9 & 0,20 & 100 & 1 & 2,06 & 2,07 & 2,08 & 2,07 & 2,17 \\
\hline 100 & 900 & 0,75 & 0,7 & 0,10 & 200 & 5 & 2,08 & 2,07 & 2,07 & 2,06 & 2,21 \\
\hline 100 & 900 & 0,75 & 0,7 & 0,15 & 50 & 10 & 2,07 & 2,07 & 2,21 & 2,39 & 2,16 \\
\hline 100 & 900 & 0,75 & 0,7 & 0,20 & 100 & 1 & 2,07 & 2,08 & 2,09 & 2,07 & 2,14 \\
\hline
\end{tabular}

Main effects plot for $\mathrm{SN}$ ratios

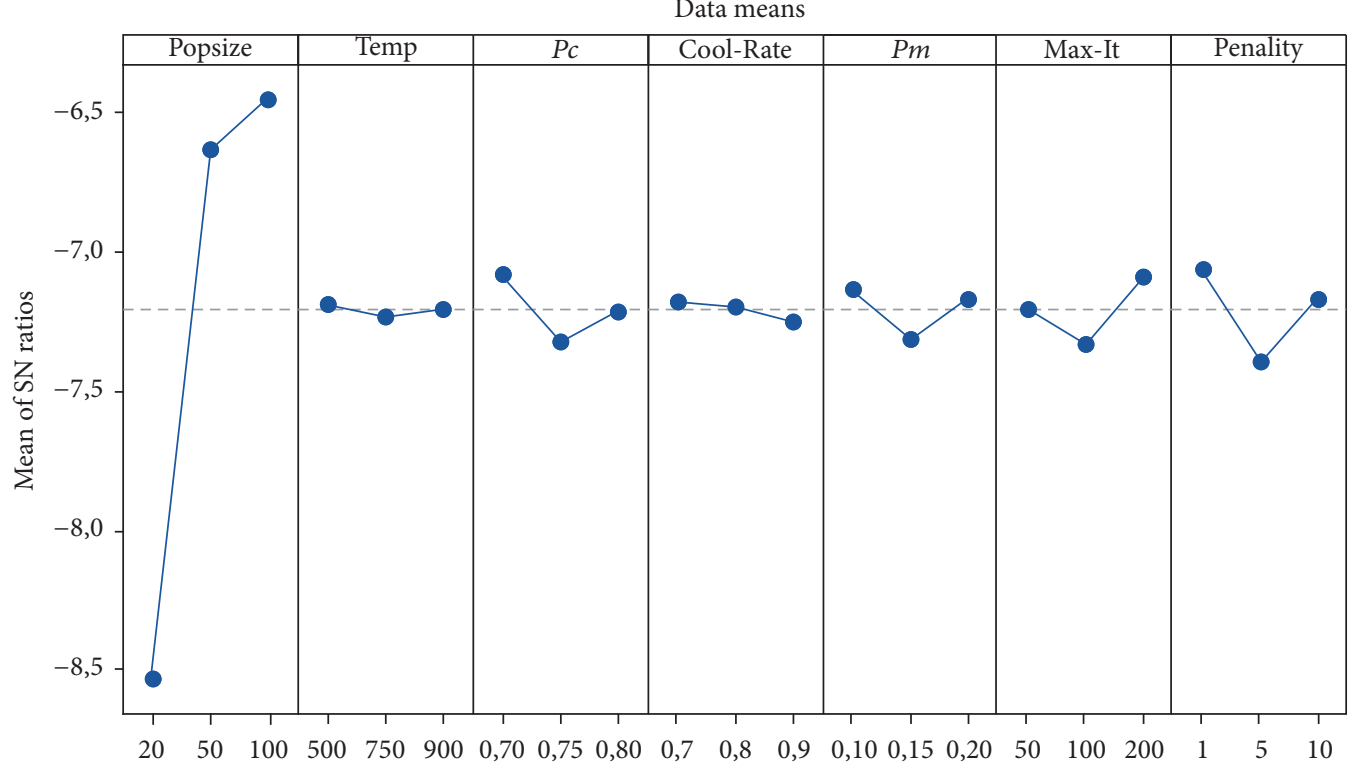

Signal-to-noise: the smaller, the better

Figure 2: The mean $S / N$ plot for each level of the HSAGA factors. 


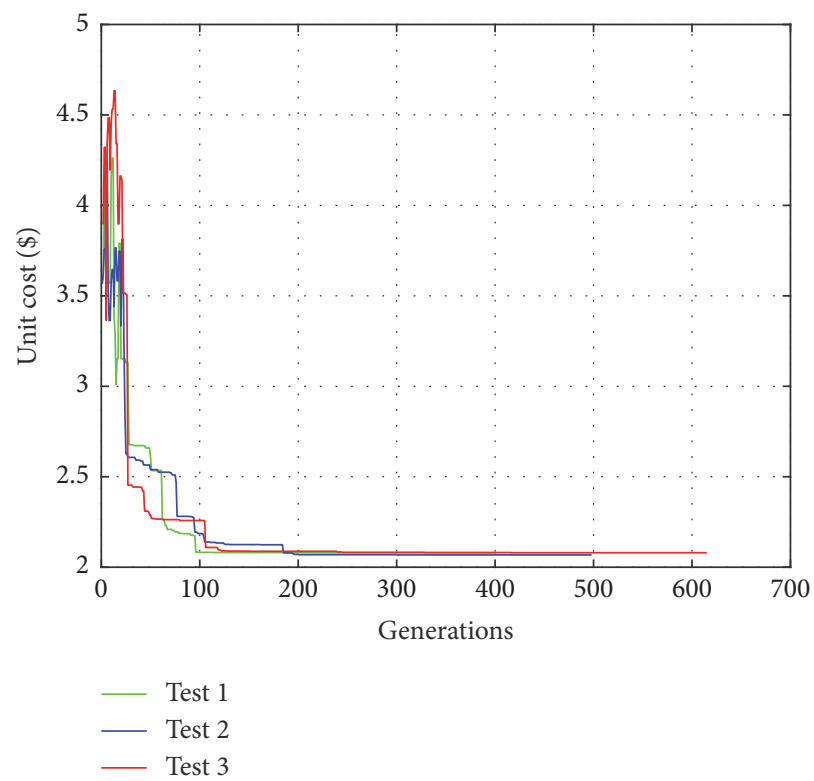

Figure 3: Trend of unit cost by HSAGA.

TABLE 4: HSAGA optimal parameters values.

\begin{tabular}{lc}
\hline Algorithm parameter & Optimal value \\
\hline Population size (Popsize) & 100 \\
Maximum iteration number & 200 \\
Crossover probability $(P c)$ & $70 \%$ \\
Mutation probability $(P m)$ & $10 \%$ \\
Initial temperature $(T)$ & 500 \\
Cooling rate $(\alpha)$ & 0.70 \\
Penalty $($ Penal) & 1 \\
\hline
\end{tabular}

\section{Nomenclature}

$U c$ :

Unit production cost, excluding material cost (\$/piece)

$C_{M}$ : Cutting cost by actual time in cutting (\$/piece)

$C_{I}$ : $\quad$ Machine idle cost due to loading and unloading operations and tool idle motion time (\$/piece)

$C_{R}: \quad$ Tool replacement cost (\$/piece)

$C_{T}: \quad$ Tool cost (\$/piece)

$V_{r}$ and $V_{s}$ : Cutting speeds in rough and finish machining, respectively $(\mathrm{m} / \mathrm{min})$

$V_{r L}$ and $V_{r U}$ : Lower and upper bounds of cutting speed in rough machining, respectively $(\mathrm{m} / \mathrm{min})$

$V_{s L}$ and $V_{s U}$ : Lower and upper bounds of cutting speed in finish machining, respectively $(\mathrm{m} / \mathrm{min})$

$d_{r}$ and $d_{s}$ : Depths of cut for each pass of rough and finish machining, respectively ( $\mathrm{mm}$ )

$d_{r L}$ and $d_{r U}$ : Lower and upper bounds of depth of roughing cut, respectively $(\mathrm{mm})$

$d_{s L}$ and $d_{s U}$ : Lower and upper bounds of depth of finishing cut, respectively ( $\mathrm{mm}$ )
TABLE 5: Obtained optimal unit cost using HSAGA approach.

\begin{tabular}{|c|c|c|c|}
\hline & Variables & Range/limit & HSAGA result \\
\hline \multirow{6}{*}{$\begin{array}{l}\text { Process } \\
\text { parameters }\end{array}$} & $V r(\mathrm{~m} / \mathrm{min})$ & $50-500$ & 111 \\
\hline & $\mathrm{fr}(\mathrm{mm} / \mathrm{rev})$ & $0.1-0.9$ & 0.565 \\
\hline & $d r(\mathrm{~mm})$ & $1.0-3.0$ & 3 \\
\hline & $V s(\mathrm{~m} / \mathrm{min})$ & $50-500$ & 171 \\
\hline & $f s(\mathrm{~mm} / \mathrm{rev})$ & $0.1-0.9$ & 0.225 \\
\hline & $d s(\mathrm{~mm})$ & $1.0-3.0$ & 3 \\
\hline \multirow{5}{*}{$\begin{array}{l}\text { Constraints for } \\
\text { rough cut }\end{array}$} & $\operatorname{Tr}(\min )$ & $\leq 25-45$ & 44.26 \\
\hline & $f r(\mathrm{Kgf})$ & $\leq 200$ & 199.16 \\
\hline & $\operatorname{Pr}(\mathrm{Kw})$ & $\leq 5$ & 4.22 \\
\hline & $\mathrm{SCr}$ & $\geq 140$ & 2278 \\
\hline & $\mathrm{Qr}\left({ }^{\circ} \mathrm{C}\right)$ & $\leq 1000$ & 866 \\
\hline \multirow{6}{*}{$\begin{array}{l}\text { Constraints for } \\
\text { finish cut }\end{array}$} & Ts & $25-45$ & 24.87 \\
\hline & Fs (Kgf) & $\leq 200$ & 98.5 \\
\hline & $P s(\mathrm{Kw})$ & $\leq 5$ & 3.25 \\
\hline & SCs & $\geq 140$ & 2164 \\
\hline & $\mathrm{Q} s\left({ }^{\circ} \mathrm{C}\right)$ & $\leq 1000$ & 857 \\
\hline & $\mathrm{SR}_{U}(\mu \mathrm{m})$ & $\leq 10$ & 5.3 \\
\hline \multirow{3}{*}{$\begin{array}{l}\text { Constraints on } \\
\text { variable } \\
\text { relations }\end{array}$} & $K_{3}$ & $\geq 1.0$ & 1.54 \\
\hline & $K_{4}$ & $\geq 2.5$ & 2.51 \\
\hline & $K_{5}$ & $\geq 1.0$ & 1 \\
\hline $\begin{array}{l}\text { Minimum cost } \\
(\$)\end{array}$ & & & 2.06 \\
\hline
\end{tabular}

$f_{\mathrm{r}}$ and $f_{\mathrm{s}}$ : Feed rates in rough and finish machining, respectively $(\mathrm{mm} / \mathrm{rev})$

$f_{\mathrm{rL}}$ and $f_{\mathrm{rU}}$ : Lower and upper bounds of feed rate in rough machining, respectively $(\mathrm{mm} / \mathrm{rev})$ 
TABLE 6: Comparison of obtained results of various optimization techniques.

\begin{tabular}{|c|c|c|c|c|c|c|c|c|c|}
\hline \multirow{2}{*}{ References } & \multirow{2}{*}{ Opti. method } & \multicolumn{6}{|c|}{ Cutting parameters } & \multirow{2}{*}{ Unit cost $(\$)$} & \multirow{2}{*}{ Viol. const. } \\
\hline & & $V_{r}$ & $f_{r}$ & $d_{r}$ & $V s$ & $f_{s}$ & $d_{s}$ & & \\
\hline Present & HSAGA & 111 & 0.565 & 3 & 171 & 0.225 & 3 & 2.06 & - \\
\hline [25] & FPA & 109.66 & 0.5655 & 3 & 169.97 & 0.2262 & 3 & 2.03 & - \\
\hline [24] & HGSS & 499.99 & 0.8939 & 2.5 & 93.89 & 0.8836 & 1 & 2.22 & Force \\
\hline [23] & Chaotic PSO & 123.34 & 0.5655 & 3 & 169.97 & 0.2262 & 3 & 1.95 & Tool life \\
\hline [22] & $\mathrm{COA}$ & 123.34 & 0.5655 & 3 & 169.978 & 0.2262 & 3 & 1.959 & Tool life \\
\hline [21] & Firefly & 98.4 & 0.82 & 3 & 162.28 & 0.25 & 3 & 1.93 & Force \\
\hline [20] & TLBO & 110 & 0.565 & 3 & 170 & 0.226 & 3 & 2.28 & Tool life \\
\hline [18] & GA & 109.663 & 0.566 & 3 & 169.986 & 0.226 & 3 & 1.12 & \\
\hline [17] & Hybrid PSO & - & - & - & - & - & - & 2.04 & \\
\hline \multirow{2}{*}{ [16] } & HDRE & - & - & - & - & - & - & 2.04 & \\
\hline & AIA & - & - & - & - & - & - & 2.12 & \\
\hline [15] & HABC & - & - & - & - & - & - & 2.04 & \\
\hline [14] & HRTLBO & - & - & - & - & - & - & 2.04 & \\
\hline \multirow{3}{*}{ [13] } & DERE & - & - & - & - & - & - & 2.04 & \\
\hline & $\mathrm{ABC}$ & - & - & - & - & - & - & 2.11 & \\
\hline & $\mathrm{DE}$ & - & - & - & - & - & - & 2.13 & \\
\hline [12] & ACO & 109.66 & 0.565 & 3 & 169.97 & 0.226 & 3 & 2.07 & - \\
\hline & GA-AIS & 133.28 & 0.8 & 2.9 & 333.23 & 0.8 & 2.5 & 1.5 & Force \\
\hline [11] & PSO & 141.7 & 0.71 & 2.8 & 330.74 & 0.71 & 2.3 & 1.6 & Force \\
\hline [10] & HPSO & 109.66 & 0.5655 & 3 & 169.97 & 0.2262 & 3 & 2.03 & Tool life \\
\hline [9] & PSO & 106.69 & 0.897 & 2 & 155.89 & 0.28 & 2 & 2.27 & - \\
\hline$[8]$ & $\begin{array}{l}\text { Analytic } \\
\text { method }\end{array}$ & 103.05 & 0.9 & 3 & 162.02 & 0.24 & 3 & 1.96 & Force \\
\hline [7] & ACO & 103.05 & 0.9 & - & 162.02 & 0.24 & - & 1.62 & Force \\
\hline [6] & GA & - & - & - & - & - & - & 2.3 & \\
\hline [5] & GA & - & - & - & - & - & - & 1.76 & \\
\hline [4] & SA-PS & - & - & - & - & - & - & 2.29 & \\
\hline
\end{tabular}

$f_{\mathrm{sL}}$ and $f_{\mathrm{sU}}$ : Lower and upper bounds of feed rate in

$N$ :

$d_{t}:$

$D, L$ :

$k_{0}$ :

$k_{t}$ :

$t_{e}$ and $t_{r}$ :

$h_{1}$ and $h_{2}$ :

$T_{r}$ and $T_{f}$

$T_{p}:$

$\Theta:$

$T_{U}, T_{L}:$

finish machining, respectively $(\mathrm{mm} / \mathrm{rev})$

Number of rough cuts, an integer

Depth of metal to be removed ( $\mathrm{mm}$ )

Diameter and length of workpiece,

respectively $(\mathrm{mm})$

Direct labor cost, including overheads

(\$/min)

Cutting edge cost (\$/edge)

Time required to exchange a tool and tool

replacement time, respectively ( $\mathrm{min}$ )

Constants pertaining to tool travel and approach/departing time, respectively (min)

Expected tool life for rough and finish machining, respectively ( $\mathrm{min}$ )

Tool life of weighted combination of $\mathrm{Tr}$ and $T s$ ( $\mathrm{min}$ )

Weight for $T p, 0<\theta<1$

respectively (min)

$p, q, r$, and $C_{0}: p=1 / \alpha, q=\beta / \alpha, r=\gamma / \alpha$, and $C_{0}=C^{1 / \alpha}$, respectively
SC: $\quad$ Limit of stable cutting region

$R: \quad \quad$ Nose radius of the cutting tool $(\mathrm{mm})$

$F_{r}$ and $F_{s}: \quad$ Cutting forces during rough and finish machining, respectively (kgf)

$\mathrm{F}_{\mathrm{U}}$ : $\quad$ Maximum allowable cutting force (kgf)

$\mathrm{K}_{1}, \nu$, and $\mu$ : Constants of the cutting force equation

$P_{r}$ and $P_{s}$ : Cutting powers during rough and finish machining, respectively $(\mathrm{kW})$

$\mathrm{P}_{\mathrm{U}}: \quad$ Maximum allowable cutting power $(\mathrm{kW})$

$\mathrm{H}: \quad$ Power efficiency

$\lambda, v: \quad$ Constants related to expression of the stable cutting region

$Q_{r}$ and $Q_{s}: \quad$ Constraint chip-tool interface temperatures during rough and finish machining, respectively $\left({ }^{\circ} \mathrm{C}\right)$

$Q_{U}: \quad$ Maximum allowable chip-tool interface temperature $\left({ }^{\circ} \mathrm{C}\right)$

$k_{2}, \tau, \varphi$, and $\delta$ : Constants related to the equation of chip-tool interface temperature

$k_{3}, k_{4}$, and $k_{5}$ : Constants for roughing and finishing parameter relations

$\mathrm{SR}_{\mathrm{U}}$ : $\quad$ Maximum allowable surface roughness (mm). 


\section{Conflicts of Interest}

The authors declare that there are no conflicts of interest regarding the publication of this paper.

\section{References}

[1] Y. C. Shin and Y. S. Joo, "Optimization of machining conditions with practical constraints," International Journal of Production Research, vol. 30, no. 12, pp. 2907-2919, 1992.

[2] N. Yusup, A. M. Zain, and S. Z. M. Hashim, "Evolutionary techniques in optimizing machining parameters: review and recent applications (2007-2011)," Expert Systems with Applications, vol. 39, no. 10, pp. 9909-9927, 2012.

[3] B. Naithani and S. Chauhan, "Mathematical modelling approach for determining optimal machining parameters in turning with computer numerical control (CNC) machines," International Journal of Computer Aided Engineering and Technology, vol. 4, no. 5, pp. 403-419, 2012.

[4] M.-C. Chen and D.-M. Tsai, "A simulated annealing approach for optimization of multi-pass turning operations," International Journal of Production Research, vol. 34, no. 10, pp. 28032825, 1996.

[5] G. C. Onwubolu and T. Kumalo, "Optimization of multipass turning operations with genetic algorithms," International Journal of Production Research, vol. 39, no. 16, pp. 3727-3745, 2001.

[6] M.-C. Chen and K.-Y. Chen, "Optimization of multipass turning operations with genetic algorithms: a note," International Journal of Production Research, vol. 41, no. 14, pp. 3385-3388, 2003.

[7] K. Vijayakumar, G. Prabhaharan, P. Asokan, and R. Saravanan, "Optimization of multi-pass turning operations using ant colony system," International Journal of Machine Tools and Manufacture, vol. 43, no. 15, pp. 1633-1639, 2003.

[8] Y.-C. Wang, "A note on 'optimization of multi-pass turning operations using ant colony system," International Journal of Machine Tools and Manufacture, vol. 47, no. 12-13, pp. 20572059, 2007.

[9] J. Srinivas, R. Giri, and S.-H. Yang, "Optimization of multi-pass turning using particle swarm intelligence," International Journal of Advanced Manufacturing Technology, vol. 40, no. 1-2, pp. 5666, 2009.

[10] A. Costa, G. Celano, and S. Fichera, "Optimization of multipass turning economies through a hybrid particle swarm optimization technique," International Journal of Advanced Manufacturing Technology, vol. 53, no. 5-8, pp. 421-433, 2011.

[11] Y. Z. Lee and S. G. Ponnambalam, "Optimisation of multipass turning operations using PSO and GA-AIS algorithms," International Journal of Production Research, vol. 50, no. 22, pp. 64996518, 2012.

[12] S. Xie and Y. Guo, "Optimisation of machining parameters in multi-pass turnings using ant colony optimisations," International Journal of Machining and Machinability of Materials, vol. 11, no. 2, pp. 204-220, 2012.

[13] A. R. Yildiz, "A comparative study of population-based optimization algorithms for turning operations," Information Sciences, vol. 210, pp. 81-88, 2012.

[14] A. R. Yildiz, "Hybrid Taguchi-differential evolution algorithm for optimization of multi-pass turning operations," Applied Soft Computing Journal, vol. 13, no. 3, pp. 1433-1439, 2013.
[15] A. R. Yildiz, "Optimization of cutting parameters in multi-pass turning using artificial bee colony-based approach," Information Sciences, vol. 220, pp. 399-407, 2013.

[16] A. R. Yildiz, "Optimization of multi-pass turning operations using hybrid teaching learning-based approach," International Journal of Advanced Manufacturing Technology, vol. 66, no. 9-12, pp. 1319-1326, 2013.

[17] A. R. Yildiz, "A novel particle swarm optimization approach for product design and manufacturing," International Journal of Advanced Manufacturing Technology, vol. 40, no. 5-6, pp. 617628, 2009.

[18] A. Aryanfar and M. Solimanpur, "Optimization of multi-pass turning operations using genetic algorithms," in Proceedings of the International Conference on Industrial Engineering and Operations Management, Istanbul, Turkey, 2012.

[19] A. Jabri, A. E. Barkany, and A. E. Khalfi, "Multi-objective optimization using genetic algorithms of multi-pass turning process," Engineering, vol. 5, no. 07, pp. 601-610, 2013.

[20] R. V. Rao and V. D. Kalyankar, "Multi-pass turning process parameter optimization using teaching-learning-based optimization algorithm," Scientia Iranica, vol. 20, no. 3, pp. 967-974, 2013.

[21] A. Bellouf, M. Assas, and I. Rezgui, "Intelligent selection of machining parameters in multipass turnings using firefly algorithm," Modelling and Simulation in Engineering, vol. 2014, Article ID 592627, 2014.

[22] M. A. Mellal and E. J. Williams, "Cuckoo optimization algorithm for unit production cost in multi-pass turning operations," International Journal of Advanced Manufacturing Technology, vol. 76, no. 1-4, pp. 647-656, 2015.

[23] P. Chauhan, M. Pant, and K. Deep, "Parameter optimization of multi-pass turning using chaotic PSO," International Journal of Machine Learning and Cybernetics, vol. 6, no. 2, pp. 319-337, 2015.

[24] R. Gayatri and N. Baskar, "Evaluating Process Parameters of Multi-Pass Turning Process Using Hybrid Genetic Simulated Swarm Algorithm," Journal of Advanced Manufacturing Systems, vol. 14, no. 4, pp. 215-233, 2015.

[25] S. Xu, Y. Wang, and F. Huang, "Optimization of multi-pass turning parameters through an improved flower pollination algorithm," International Journal of Advanced Manufacturing Technology, vol. 88, pp. 1-12, 2016.

[26] S. K. Hati and S. S. Rao, "Determination of Optimum Machining Conditions-Deterministic and Probabilistic Approaches," Journal of Engineering for Industry, vol. 98, no. 1, pp. 354-359, 1976.

[27] R. V. Narang and G. W. Fischer, "Development of a framework to automate process planning functions and to determine machining parameters," International Journal of Production Research, vol. 31, no. 8, pp. 1921-1942, 1993.

[28] D. E. Goldberg, Genetic Algorithms in Search, Optimization and Machine Learning, Addison-Wesley, New York, NY, USA, 1998.

[29] S. Kirkpatrick, J. Gelatt, and M. P. Vecchi, "Optimization by simulated annealing," American Association for the Advancement of Science. Science, vol. 220, no. 4598, pp. 671-680, 1983.

[30] S. M. Phadke, Quality Engineering Using Robust Design, Prentice Hall, New York, NY, USA, 1989.

[31] G. G. Taguchi, S. Chowdhury, and S. Taguchi, Robust Engineering, McGraw-Hill, New York, NY, USA, 2000. 


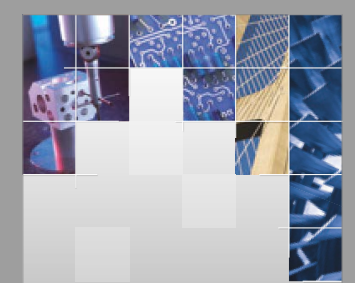

\section{Enfincering}
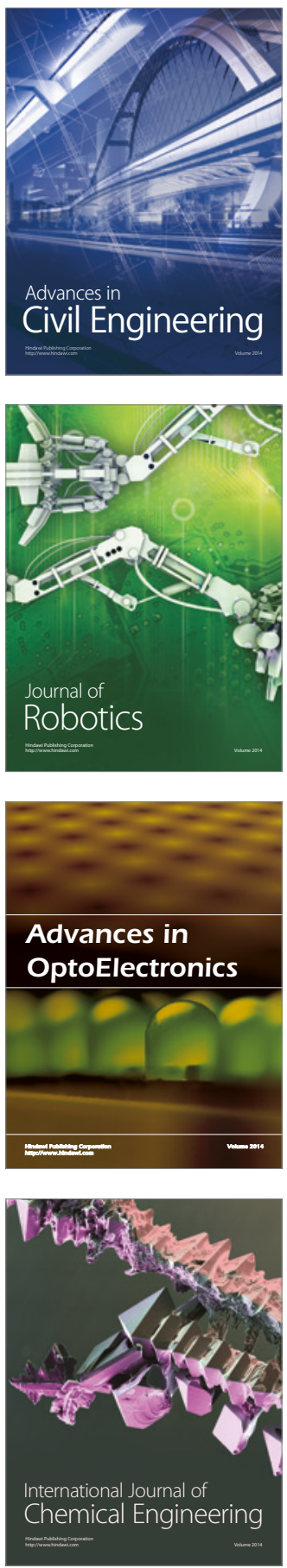

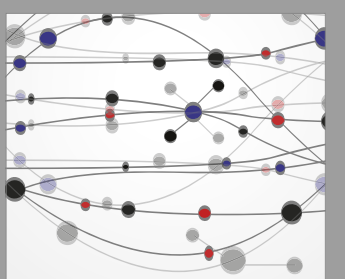

The Scientific World Journal

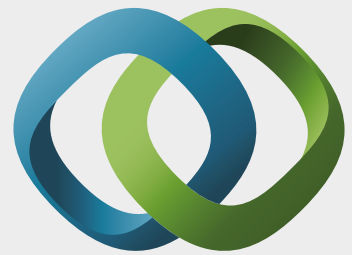

\section{Hindawi}

Submit your manuscripts at

https://www.hindawi.com
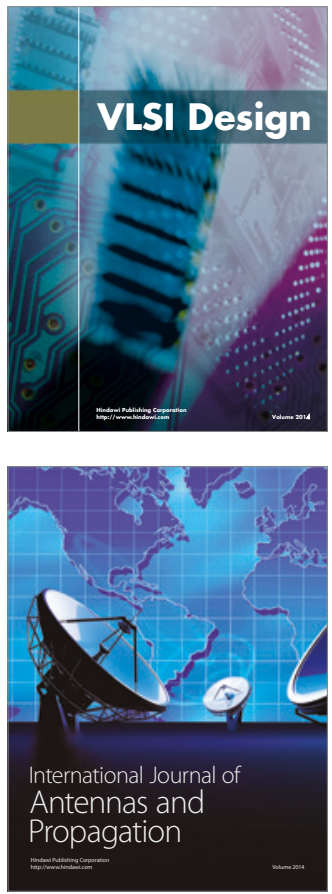

\section{Rotating}

Machinery
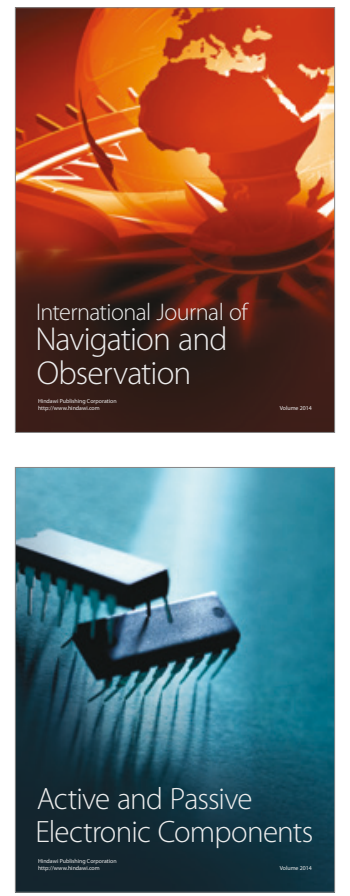
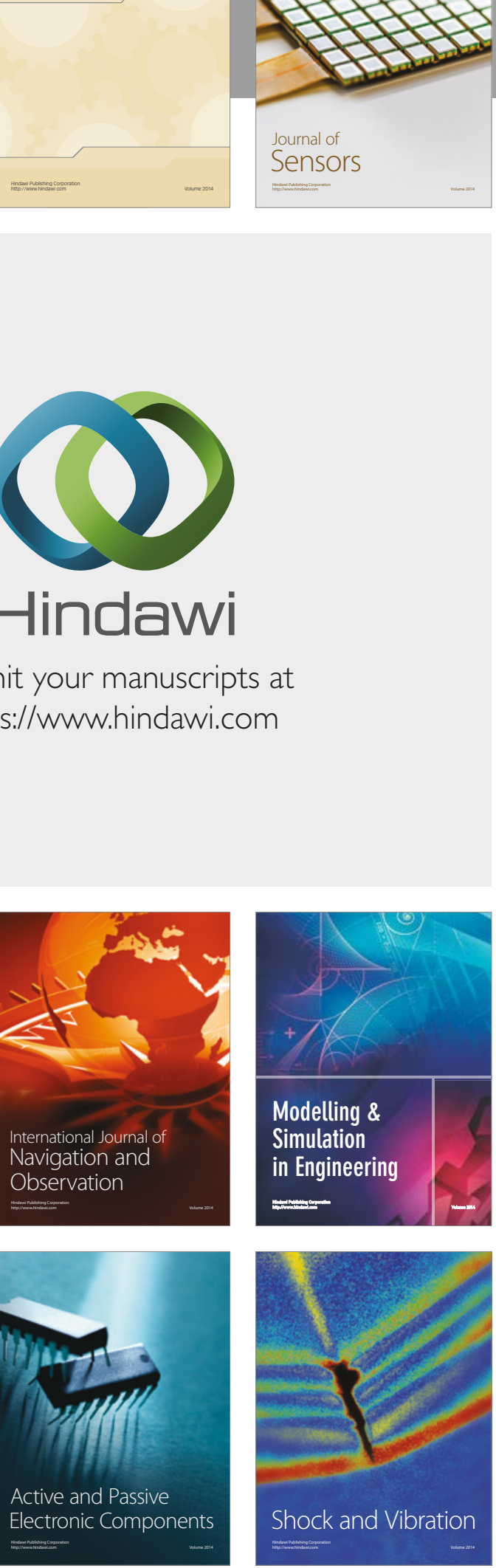
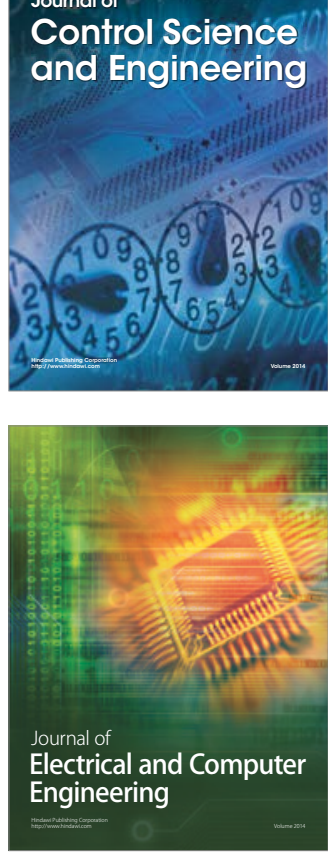

Distributed

Journal of

Control Science

and Engineering
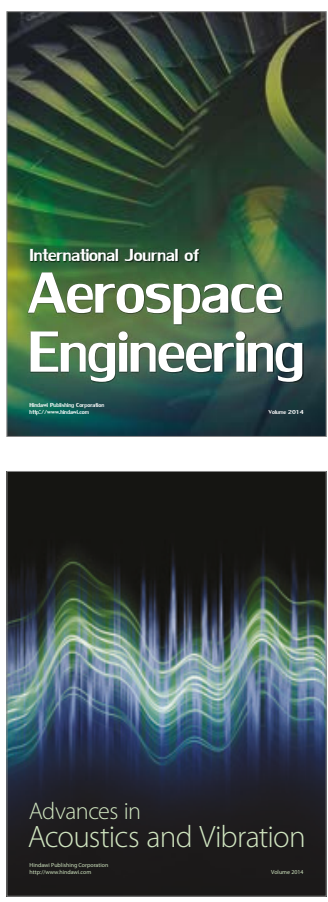

Sensor Networks 